\title{
The significance of socio-economic characteristics for adult seasonal body-weight fluctuations: a study in north-western Benin
}

\author{
BY MARTI J. VAN LIERE ${ }^{1}$, ERIC-ALAIN D. ATEGBO ${ }^{2}$, JAN HOORWEG ${ }^{3}$, \\ ADEL P. DEN HARTOG' AND JOSEPH G. A. J. HAUTVAST ${ }^{1}$ \\ ${ }^{1}$ Department of Human Nutrition, Agricultural University of Wageningen, PO Box 8129, $6700 \mathrm{EV}$ \\ Wageningen, The Netherlands \\ ${ }^{2}$ Department of Human Nutrition and Food Sciences, Faculty of Agricultural Sciences, National \\ University of Benin, PO Box 526, Cotonou, Republic of Benin \\ ${ }^{3}$ African Studies Centre, PO Box 9555, 2300 RB Leiden, The Netherlands
}

(Received 9 August 1993 - Revised 29 November 1993 - Accepted 14 January 1994)

\begin{abstract}
Large variations in seasonal body-weight fluctuations have been described for individuals from different households living and working under comparable circumstances. In the present study the relationship between socio-economic household characteristics and seasonal body-weight fluctuations of individual members of rural Beninese households were studied. No significant correlation was found for bodyweight fluctuation between the two study years, nor for body-weight fluctuation of men and women belonging to the same household. When comparing dichotomized socio-economic classes for relative body-weight fluctuation of men and women in both study years, no consistent trends were observed for both years nor for both sexes. The distribution of subjects with a consistent high weight fluctuation over the two study years did not differ between socio-economic groups. In conclusion it may be stated that there were no indications that socio-economic characteristics play a determining role in the magnitude of body-weight fluctuation of this study population, despite the large variations observed in the latter. Therefore it is most likely that other factors decide the weight fluctuations of individuals, health and sanitation being the most likely candidates.
\end{abstract}

Socio-economic characteristics: Seasonal body-weight fluctuation: Rural Benin

Seasonal food shortages are an annual recurring event in many developing countries (Annegers, 1973; Longhurst, 1986; Sahn, 1989). The shortages can be of such a magnitude that body-weight losses of $2-6 \%$ of total body-weight occur (Rosetta, 1986; Dugdale \& Payne, 1987; Durnin et al. 1990; Ferro-Luzzi et al. 1990; Schultink et al. 1990). It has been noticed that large variations in body-weight losses between households occur, even when these households live and work in comparable situations.

Socio-economic variables have often been studied as determinants of child and adult nutritional status but conclusions from these studies are not consistent. Some studies have reported a relationship between farm size, cropping pattern, family income, age, birth interval or mother's nutritional knowledge and the extent of chronic malnutrition (Valverde et al. 1977; Nabarro, 1984; Haaga, 1986; Christian et al. 1989). Other studies have not found evidence for an interaction between socio-economic and seasonal influences on child nutrition (McNeill et al. 1988; Kennedy \& Oniang'o, 1990). So far, most studies on adults have used only one body-weight measurement as a reference for studying the relationship between social environment and nutritional status. This may be questioned as 
body-weight variations often occur in adult people, both in the Western world ('slimming exercises') and in the developing world ('seasonal food shortages').

Studies looking at seasonal changes in food supply and physical activities, and adaptations of individuals to these seasonal fluctuations, have so far given little or no attention to the relationship with socio-economic variables (Ferro-Luzzi et al. 1990; Schultink, 1991; Ategbo, 1993). An exception is the study of Niemeyer et al. (1991) who reported that women in poorer households showed the smallest seasonal fluctuations in body-weight, probably due to overall low food intake. Women from middle income groups, who depended mostly on farming, showed important weight fluctuation.

The objective of the present study is to look into the relationship between socio-economic household characteristics and seasonal body-weight fluctuations of individual members of rural Beninese households.

\section{SUBJECTS AND METHODS}

\section{Study area}

The research was conducted in five villages of the commune of Manta, in the north-western part of Benin. The area was chosen mainly because of its unimodal climate (i.e. one rainy season and therefore one single cropping season per year), existing seasonal fluctuations in body-weight (Schultink, 1991), absence of intervention programmes and reasonable accessibility of the area. Annual rainfall ranges from $1000-1300 \mathrm{~mm}$, with a concentration in the months May to September. Average daily temperature varies between $26^{\circ}$ (August) and $36^{\circ}(\mathrm{March})$. The region is part of the Guinean savanna zone, open area with scattered trees. Trees such as the African locust (néré; Parkia biglobosa) and the shea tree (karité; Butyrospermum parkii) provide valuable tree crops for the population. The African locust provides seeds which are used to prepare a condiment which is an important ingredient for sauces. These seeds can be exchanged for sorghum during the so-called hungry season, the period of food shortage, and flour from the locust pods can be consumed as a "hungry' food. Nuts from the shea tree are processed in order to get shea butter which is the main fat source in the diet. The population are mainly subsistence farmers and about $65 \%$ of the energy intake comes from their own food production. Main food crops are sorghum (Sorghum spp.), millet (Pennisetum spp.) and 'hungry rice', also called fonio (Digitaria exilis), a grass-like cereal. The only cash crop is groundnuts (Arachis hypogaea). The harvest season is from October to December, except for fonio which often can be harvested as early as half-way through September. The hungry season starts at the end of July or beginning of August and ends with the harvest of fonio in September. Income-generating activities for men mainly consist of handicraft and construction works whereas women are mostly engaged in small trade of raw or processed foods such as shea butter in the market. Livestock is kept as capital investment and serves as bride price, or is used for ceremonial purposes.

\section{Subjects}

A group of 214 households was selected from the population of five villages (about 4000 inhabitants) meeting criteria concerning subsistence farming and permanent residence in the study area. Full data sets on socio-economic household characteristics were obtained for 214 households in 1990 and 210 households in 1991.

After selection of the study population in mid 1989, 198 men and 214 women participated in the research. They were all involved in the longitudinal body-weight study carried out over a period of 2 years between January 1990 and December 1991. When women became pregnant during the observation period, data collection was continued but 
Table 1. Socio-economic characteristics of total study population in 1990 and 1991

\begin{tabular}{|c|c|c|}
\hline & $\begin{array}{c}1990 \\
(n 214)\end{array}$ & $\begin{array}{c}1991 \\
(n 210)\end{array}$ \\
\hline \multicolumn{3}{|l|}{ Demographic characteristics } \\
\hline Age of head of household (years) & 41 & 42 \\
\hline Education level of head ( $\%$ no school) & 0.95 years $(77 \%)$ & 0.93 years $(77 \%)$ \\
\hline Household size (no. members) & $7 \cdot 2$ & $7 \cdot 4$ \\
\hline Infant ratio $(<6: \geqslant 6$ years $)$ & 0.28 & 0.31 \\
\hline \multicolumn{3}{|l|}{ Farm characteristics } \\
\hline Cereal stock $(\mathrm{kg})^{*}$ & 605 (median) & $500($ median$)$ \\
\hline Groundnut cultivation $(\%)$ & $49 \%$ & $51 \%$ \\
\hline \multicolumn{3}{|l|}{ No. African locust trees* } \\
\hline 0 & $28 \%$ & $28 \%$ \\
\hline $1-5$ & $28 \%$ & $28 \%$ \\
\hline $6-10$ & $20 \%$ & $20 \%$ \\
\hline$>10$ & $24 \%$ & $24 \%$ \\
\hline \multicolumn{3}{|l|}{ Livestock } \\
\hline Only poultry & $7 \%$ & $3 \%$ \\
\hline Sheep/goat & $43 \%$ & $43 \%$ \\
\hline $1-5$ cows & $40 \%$ & $43 \%$ \\
\hline$>5$ cows & $10 \%$ & $11 \%$ \\
\hline \multicolumn{3}{|l|}{ Off-farm characteristics } \\
\hline \multicolumn{3}{|l|}{ Income level, man, wet season: } \\
\hline None & $81 \%$ & $83 \%$ \\
\hline $1-10000 \mathrm{Fcfa}$ & $7 \%$ & $6 \%$ \\
\hline $10000-50000$ Fcfa & $8 \%$ & $9 \%$ \\
\hline $50000-100000 \mathrm{Fcfa}$ & $2 \%$ & $1 \%$ \\
\hline$>100000 \mathrm{Fcfa}$ & $1 \%$ & $1 \%$ \\
\hline \multicolumn{3}{|l|}{ Income level, man, dry season: } \\
\hline None & $68 \%$ & $74 \%$ \\
\hline $1-10000 \mathrm{Fcfa}$ & $13 \%$ & $8 \%$ \\
\hline $10000-50000$ Fcfa & $15 \%$ & $16 \%$ \\
\hline $50000-100000$ Fcfa & $2 \%$ & $3 \%$ \\
\hline$>100000 \mathrm{Fcfa}$ & $1 \%$ & - \\
\hline \multicolumn{3}{|l|}{ Income level, woman, wet season: } \\
\hline None & $79 \%$ & $80 \%$ \\
\hline $1-10000 \mathrm{Fcfa}$ & $8 \%$ & $12 \%$ \\
\hline $10000-50000 \mathrm{Fcfa}$ & $11 \%$ & $8 \%$ \\
\hline $50000-100000$ Fcfa & $2 \%$ & - \\
\hline$>100000 \mathrm{Fcfa}$ & $1 \%$ & - \\
\hline \multicolumn{3}{|l|}{ Income level, woman, dry season: } \\
\hline None & $59 \%$ & $62 \%$ \\
\hline $1-10000$ Fcfa & $22 \%$ & $28 \%$ \\
\hline $10000-50000$ Fcfa & $16 \%$ & $10 \%$ \\
\hline $50000-100000 \mathrm{Fcfa}$ & $2 \%$ & $1 \%$ \\
\hline$>100000$ & $1 \%$ & - \\
\hline
\end{tabular}

* For cereal stock, data were available on 193 households and for African locust tree on 103 households.

the results of these women were excluded from analysis. Drop-out of men occurred mainly due to seasonal migration. Complete data sets on body weights for both years were obtained for 114 women and 135 men.

For 104 households in 1990 and seventy-four households in 1991, anthropometric information on both husband and wife was available. 


\section{Design and methods}

Men and women were weighed fortnightly in 1990; in 1991 weighing frequency was reduced to once monthly. Weighing was carried out at a central place in each village between 06.30 and 08.00 hours, using Seca platform spring balances attached to a wooden board. The balances were calibrated at every weighing session using test weights of 40,50 or $60 \mathrm{~kg}$. The subjects wore a minimum of clothing and body weight was measured to the nearest $0.5 \mathrm{~kg}$ (no correction was made for the clothing which was virtually the same throughout all weighing sessions).

At the beginning of each year a general questionnaire on socio-economic household characteristics was administered to each household. Questions concerned demographic characteristics (household composition, educational level), farm characteristics (livestock ownership, ownership of trees, cash crop cultivation) and off-farm income level of men and women in dry and rainy seasons (Table 1 ).

Cereal stocks in granaries were assessed in February as an estimate of the post-harvest stock. Cereals are dried for a couple of weeks after the harvest and are stocked in the granaries by the end of January or in February. At that time stocks are generally at their maximum. A photograph of each granary provided the necessary sizes on scale in order to calculate volume. The assumption was made that the form of the granary resembles two cones with their bases against each other. Inside the granary, height of the empty part was measured and the empty volume thus calculated was subtracted from the total in order to obtain the volume of the filled part. Only compartments containing cereals (sorghum, millet, fonio and rice) were measured. Cereal availability for each household was estimated from calculations of the volume of the filled part of the granary. Calculations were carried out using the Lotus-123 computer program. Conversion factors from volume into weight, determined by experiment for each cereal, were as follows $(\mathrm{kg} / \mathrm{l})$ : sorghum (ears) $0 \cdot 17$; millet (threshed) 0.81 ; fonio 0.37 ; rice 0.42 . Energy values for the different cereals were $(\mathrm{MJ} / \mathrm{kg}$ ): sorghum (ears) $14 \cdot 4$; millet (threshed) $15 \cdot 8$; fonio $14 \cdot 4$; rice $15 \cdot 4$.

\section{Data analyses and statistics}

Group averages for body weight per measurement round are used to define the maximum and minimum values of individual body weight. Maximum and minimum periods were defined in 1990 as the periods with the three highest and lowest group averages and in 1991 as the two highest and lowest values. For men these periods were: 1990, maximum March, minimum 15 September-15 October; 1991, maximum 15 April-15 May, minimum 15 September-15 October. For women the periods were: 1990, maximum 15 February-15 March, minimum October; 1991, maximum 15 April-15 May, minimum 15 August-15 September. For individuals, absolute seasonal body-weight fluctuation was calculated as the difference between the highest value within the defined maximum period and the lowest value within the defined minimum period. Body-weight fluctuation was also expressed as a percentage of the average annual body weight. Individuals with two or more missing values in one of the periods were excluded from analysis.

Pair-wise comparison of anthopometric variables between the two years was done with the paired samples $t$ test for average body weight and relative body-weight fluctuation and with the Wilcoxon matched-pairs signed-ranks test for absolute body-weight fluctuation. Correlations between percentage body-weight fluctuation during the two respective study years as well as between men and women belonging to the same household were determined by Pearson's correlation coefficient $r_{p}$.

Dichotomized classifications were enforced on off-farm and farm characteristics as follows: cows, yes/no; income, yes/no; cash crop, yes/no; African locust trees, $\leqslant 5 />5$; 


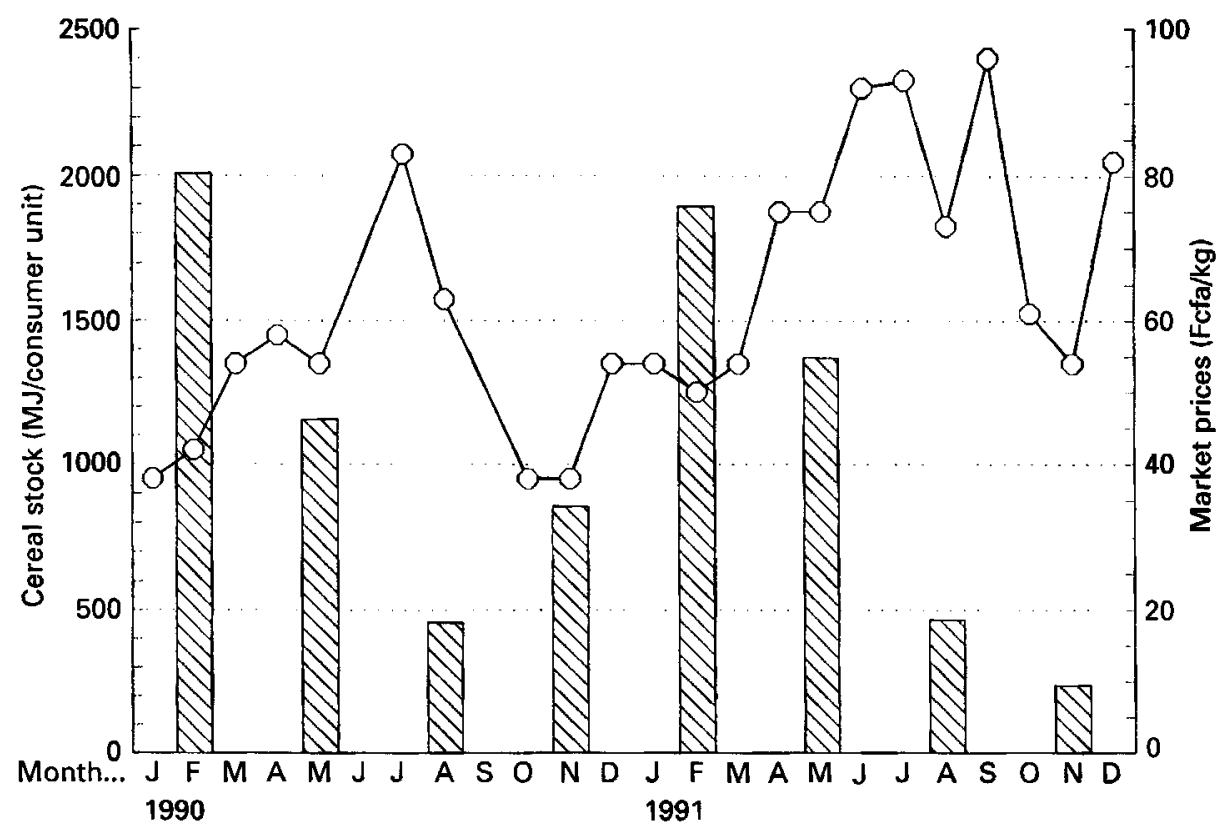

Fig. 1. Seasonal changes in household cereal stock $(\mathbb{\nabla})$ and cereal market prices $(O)$ in Manta, north-western Benin, during the years 1990 and 1991 . Values for cereal stock are median values.

infant ratio, $\leqslant 0 \cdot 25 />0 \cdot 25$; age head of household, $\leqslant 30 />30$ years; household size, $\leqslant 7 />7$; education head, yes/no; cereal stock, $\leqslant 500 \mathrm{~kg} />500 \mathrm{~kg}$. The resulting subgroups were compared with regard to relative body-weight fluctuations in 1990 and 1991 and for incidence of subjects with a high weight fluctuation (above the group average) in both years. Differences were tested with help of the Student's $t$ test and the $\chi^{2}$ test for non-parametric data.

\section{RESULTS}

Evidence for seasonality in food availability is shown in Fig. 1. This figure presents cereal prices and cereal stocks during the two study years 1990 and 1991, and shows low stocks and high prices in the hungry seasons. Estimates of cereal stocks equal 1900$2000 \mathrm{MJ} /$ consumer unit at the beginning of a year and about $460 \mathrm{MJ} /$ consumer unit during the hungry season. November 1991 shows a lower cereal stock $(240 \mathrm{MJ})$ than November 1990 (850 MJ).

The seasonal fluctuations in body weight are shown in Table 2. Average absolute fluctuations were $3.9 \mathrm{~kg}$ for men and $2.8 \mathrm{~kg}$ for women in 1990 and $2.9 \mathrm{~kg}$ for men and $2.5 \mathrm{~kg}$ for women in 1991. Individual fluctuation ranged from a weight gain of $1.5 \mathrm{~kg}$ to a loss of $10.0 \mathrm{~kg}$ for men and from a weight gain of $4.5 \mathrm{~kg}$ to a loss of $9.0 \mathrm{~kg}$ for women, corresponding with a range for relative fluctuation of $9 \%$ weight gain and $16 \%$ weight loss.

Comparison between the two years showed that for women there was no significant difference for either of the anthropometric indicators, but for men both indicators showed significantly lower values in 1991 than in 1990 (Table 2). Since relative and absolute bodyweight changes gave similar results, the further analyses are mostly concerned with relative body-weight fluctuation ( $\%$ ) because of its normal distribution. Looking at rank correlation 
Table 2. Seasonal, absolute and relative body-weight fluctuation for men and women in 1990 and 1991, in north-western Benin

\begin{tabular}{|c|c|c|c|c|c|c|c|c|}
\hline & \multicolumn{4}{|c|}{$\operatorname{Men}(n 135)$} & \multicolumn{4}{|c|}{ Women (n 114) } \\
\hline & \multicolumn{2}{|c|}{1990} & \multicolumn{2}{|l|}{1991} & \multicolumn{2}{|c|}{1990} & \multicolumn{2}{|c|}{1991} \\
\hline & Mean & $\mathrm{SD}$ & Mean & SD & Mean & SD & Mean & $\mathrm{SD}$ \\
\hline Average body weight $(\mathrm{kg})$ & $60 \cdot 5$ & $7 \cdot 2$ & $60 \cdot 1^{* * *}$ & $7 \cdot 0$ & $51 \cdot 6$ & $4 \cdot 7$ & $51 \cdot 7$ & $4 \cdot 7$ \\
\hline Body-weight fluctuation $(\mathrm{kg})$ & 3.9 & $2 \cdot 2$ & $2 \cdot 9 * * *$ & $1 \cdot 8$ & $2 \cdot 8$ & $2 \cdot 4$ & $2 \cdot 5$ & $2 \cdot 2$ \\
\hline Range of weight fluctuation $(\mathrm{kg}) \dagger$ & \multicolumn{2}{|c|}{$-1 \cdot 5,+10 \cdot 0$} & \multicolumn{2}{|c|}{$-1 \cdot 5,+9 \cdot 0$} & \multicolumn{2}{|c|}{$+4 \cdot 5,-7 \cdot 5$} & \multicolumn{2}{|c|}{$+1 \cdot 5,-9.0$} \\
\hline Relative weight fluctuation $(\%)$ & $6 \cdot 4$ & $3 \cdot 4$ & $4 \cdot 8 * * *$ & $3 \cdot 0$ & $5 \cdot 4$ & $4 \cdot 6$ & $4 \cdot 9$ & $4 \cdot 1$ \\
\hline Range of relative weight fluctuation (\%)† & \multicolumn{2}{|c|}{$-2 \cdot 6,+15 \cdot 7$} & \multicolumn{2}{|c|}{$-2 \cdot 5,+13 \cdot 1$} & \multicolumn{2}{|c|}{$+9 \cdot 0,-15 \cdot 8$} & \multicolumn{2}{|c|}{$+3 \cdot 0,-16 \cdot 1$} \\
\hline
\end{tabular}

Mean values were significantly different from those for $1990:{ }^{* * *} P<0.001$.

$\dagger$ Due to the definition of body-weight fluctuation, weight gain has a minus sign and weight loss has a plus sign.

of anthropometric indicators between the two years, no significant correlation existed between relative body-weight fluctuations in 1990 and 1991 (for men $r_{p} 0 \cdot 11$, for women $\left.r_{p} 0 \cdot 06\right)$.

Relative body-weight fluctuations of men and women belonging to the same household who may be assumed to have the same socio-economic characteristics, were not related. Correlations were not significant: $r_{p} 0.03\left(n\right.$ 104) for 1990 and $r_{p} 0.24(n 74)$ for 1991 values.

The breakdown by various socio-economic characteristics reveals only a few significant differences in relative weight fluctuation (for high infant ratio, income in the dry season, possession of tree crops; Table 3). Moreover, there is no systematic pattern of relationships to be discerned, while results happen to differ for men and women as well as for separate years. Similarly, combined results for 1990 and 1991, i.e. the percentage of subjects with high fluctuation in both years, show a relationship only with infant ratio and weight fluctuation of men.

\section{DISCUSSION}

The trends in food prices and food availability (Fig. 1) indicate that seasonality in food availability was more pronounced during the second year of our study. Cereal prices rose higher during the hungry season of 1991 whereas the cereal stocks fell 15-20\% lower than in 1990. (Price fluctuation cannot be due to inflation since the Fcfa is related to the French franc $(1 \mathrm{FF}=50 \mathrm{Fcfa})$ and economic reports show that there was no question of inflation during the study period (Université Nationale du Bénin, 1992).) Depletion of stocks continued in 1991 until November whereas in November 1990 cereal stocks had already increased because of the harvest of fonio.

The magnitude of body-weight fluctuations of men and women in the present study is generally in line with the existing literature (Rosetta, 1986; Teokul et al. 1986; Ferro-Luzzi et al. 1990). The present study attempted to take the subject one step further by looking at possible relationships between socio-economic household characteristics and seasonal weight fluctuations. This effort met with little success: results show a lack of consistency of findings and an absence of relations.

First, seasonality in food availability in stock and market being more pronounced in the second year, a larger weight fluctuation was expected in 1991. However, men showed a smaller weight fluctuation in 1991, the year with more seasonal stress, than in 1990, and for women there was no significant difference between the two years. Ategbo (1993) has 
Table 3. Relative body-weight fluctuations and percentage of subjects with a body-weight fluctuation higher than group average in both 1990 and 1991, for groups of men and women with different socio-economic characteristics in Manta, north-western Benin $\dagger$

\begin{tabular}{|c|c|c|c|c|c|c|}
\hline & \multicolumn{3}{|c|}{ Men } & \multicolumn{3}{|c|}{ Women } \\
\hline & $\begin{array}{l}\text { Weight } \\
\text { fluctuation } \\
\text { in } 1990 \\
(\%)\end{array}$ & $\begin{array}{c}\text { Weight } \\
\text { fluctuation } \\
\text { in } 1991 \\
(\%)\end{array}$ & $\begin{array}{c}\text { High } \\
\text { fluctuation } \\
\text { in } 1990 \text { and } \\
1991(\%)\end{array}$ & $\begin{array}{c}\text { Weight } \\
\text { fluctuation } \\
\text { in } 1990 \\
(\%)\end{array}$ & $\begin{array}{l}\text { Weight } \\
\text { fluctuation } \\
\text { in } 1991 \\
(\%)\end{array}$ & $\begin{array}{c}\text { High } \\
\text { fluctuation } \\
\text { in } 1990 \text { and } \\
1991(\%)\end{array}$ \\
\hline \multicolumn{7}{|c|}{$\begin{array}{l}\text { Age of head of } \\
\text { household (years) }\end{array}$} \\
\hline$\leqslant 30$ & 5.5 & 3.9 & 19 & $4 \cdot 2$ & 4.5 & 24 \\
\hline$>30$ & 6.5 & 4.9 & 32 & 5.6 & $5 \cdot 0$ & 28 \\
\hline \multicolumn{7}{|c|}{$\begin{array}{l}\text { Household size } \\
\text { (no.) }\end{array}$} \\
\hline$\leqslant 7$ & 6.0 & 4.7 & 24 & 5.2 & 4.8 & 24 \\
\hline$>7$ & 7.0 & 4.9 & 38 & 5.7 & $5 \cdot 0$ & 30 \\
\hline \multicolumn{7}{|l|}{ Education } \\
\hline 0 year & 6.6 & $5 \cdot 0$ & 34 & $5 \cdot 3$ & $4 \cdot 8$ & 24 \\
\hline$\geqslant 1 \mathrm{yr}$ & 5.5 & 40 & 16 & 6.1 & $5 \cdot 5$ & 43 \\
\hline \multirow{2}{*}{\multicolumn{7}{|c|}{ Infant ratio }} \\
\hline \multicolumn{2}{|c|}{$(<6$ yrs $: \geqslant 6$ years $)$} & & & & & \\
\hline$\leqslant 0.25$ & 7.5 & $5 \cdot 1$ & 39 & 5.6 & $5 \cdot 6$ & 26 \\
\hline$>0.25$ & $5 \cdot 5^{*}$ & $4 \cdot 6$ & $22^{*}$ & $5 \cdot 2$ & $4 \cdot 5$ & 28 \\
\hline \multicolumn{7}{|l|}{ Cash crop } \\
\hline No & $6 \cdot 7$ & 4.9 & 27 & 5.5 & $4 \cdot 7$ & 31 \\
\hline Yes & 6.0 & $4 \cdot 7$ & 32 & $5 \cdot 3$ & $5 \cdot 1$ & 24 \\
\hline \multicolumn{7}{|c|}{ Tree crop (locust) } \\
\hline$\leqslant 5$ & $7 \cdot 0$ & $4 \cdot 0$ & 22 & 3.6 & $6 \cdot 3$ & 27 \\
\hline$>5$ & $6 \cdot 2$ & $5 \cdot 0$ & 32 & $5.9 *$ & $4 \cdot 6^{*}$ & 27 \\
\hline \multicolumn{7}{|l|}{ Cereal stock } \\
\hline$\leqslant 500 \mathrm{~kg}$ & 6.6 & 4.8 & 26 & 6.0 & $4 \cdot 8$ & 22 \\
\hline$>500 \mathrm{~kg}$ & $6 \cdot 3$ & $4 \cdot 7$ & 32 & $5 \cdot 1$ & 5.0 & 30 \\
\hline \multicolumn{7}{|l|}{ Livestock } \\
\hline No cows & 5.8 & 42 & 26 & 5.6 & $4 \cdot 7$ & 26 \\
\hline Yes cows & 6.9 & $5 \cdot 2$ & 32 & $5 \cdot 2$ & $5 \cdot 1$ & 29 \\
\hline \multicolumn{7}{|c|}{$\begin{array}{l}\text { Income, men, } \\
\text { dry season }\end{array}$} \\
\hline No & $6 \cdot 3$ & 4.9 & 30 & 6.0 & $5 \cdot 0$ & 30 \\
\hline Yes & $6 \cdot 5$ & $4 \cdot 2$ & 27 & $2 \cdot 5^{*}$ & $4 \cdot 4$ & 16 \\
\hline \multicolumn{7}{|c|}{$\begin{array}{l}\text { Income, men, } \\
\text { wet season }\end{array}$} \\
\hline No & $6 \cdot 3$ & 4.9 & 28 & 5.7 & 5.0 & 31 \\
\hline Yes & 7.2 & $4 \cdot 2$ & 44 & 3.5 & $4 \cdot 3$ & 0 \\
\hline \multicolumn{7}{|c|}{$\begin{array}{l}\text { Income, women, } \\
\text { dry season }\end{array}$} \\
\hline No & $6 \cdot 4$ & 4.8 & 28 & 5.5 & 5.0 & 27 \\
\hline Yes & $6 \cdot 1$ & $5 \cdot 1$ & 35 & 5.2 & 3.7 & 28 \\
\hline \multicolumn{7}{|c|}{$\begin{array}{l}\text { Income, women, } \\
\text { wet season }\end{array}$} \\
\hline No & 6.4 & 4.8 & 28 & 5.7 & 4.9 & 28 \\
\hline Yes & 6.0 & $4 \cdot 8$ & 39 & 3.5 & $4 \cdot 3$ & 21 \\
\hline
\end{tabular}

Mean values were significantly different between socio-economic groups: ${ }^{*} P<0.05$.

$\dagger$ For details of subjects and procedures, see pp. 480-482. 
suggested that the lower body-weight fluctuation of men in 1991 should be attributed to a change in activity pattern from year to year. In 1991 the fonio crop failed and men spent 1-2 weeks less on energy-demanding harvest tasks than in 1990.

Second, it turns out that individual body-weight fluctuations show little consistency over the two years. Neither for men nor for women is there a significant correlation between weight fluctuation in the two years. This means that a large body-weight fluctuation in one year says little or nothing about the fluctuation that an individual will experience the next year.

Third, body-weight fluctuations of men and women within the same household do not show a significant correlation either. This in itself is not surprising because of the different gender roles in rural African households which often function only partly as one economic unit (Guyer, 1986). Labour demands on men and women differ with the season, income earned does not necessarily add up to one communal household resource base, and intrahousehold food distribution is often uneven (Kennedy, 1983).

The results of the above analyses make the chance of finding relationships between bodyweight fluctuation and socio-economic characteristics minimal. Indeed no consistent relationships were found with variables representing productive resources such as food production, commercial cropping and livestock (farm characteristics), income (off-farm characteristics) as well as non-productive factors such as household size (demographic characteristics). Although there were significant relationships with incidental variables (infant score, income and tree crops) this is no more than could be expected by chance when testing a large number of relationships (Table 3). Moreover, these relationships were not consistent over the two study years or over the two sexes. Further analysis with help of a combination variable of farm and off-farm characteristics did not reveal any relationship with weight fluctuation either.

The question that needs to be addressed therefore is what this lack of evidence for relationships between socio-economic characteristics and body-weight fluctuation means. Two scenarios are possible: first, that the study was not sensitive enough and failed to prove relationships that nevertheless exist; second, that relationships are indeed absent or too weak to be of importance.

In the first scenario one could still expect to find certain weak trends, which however were not seen. The statistical power of the study to detect a difference of $1 \%$ in body-weight fluctuation of two different socio-economic groups is $80 \%$. Still, it is true that the study population consists of a rather homogeneous group of subsistence farmers with only limited socio-economic differentiation. However, the variables that did show sufficient differentiation (cereal stock, livestock) were also not related to fluctuation in body weight. The first scenario is the more questionable because insufficient socio-economic differentiation cannot explain why no relationship was found between weight fluctuation of individuals in one year and in the other.

In the second scenario the relationships were weak and inconsistent or indeed absent. It is possible that the two years were drastically different with regard to a household's resource base (livestock, off-farm income, harvest) or natural events, such as heavy rainfall, and therefore incomparable. This was not observed by the first author who lived in the study area during the years of field work. Although there was a difference of degree in food availability between the two years, they were highly correlated (Spearman rank-order correlation coefficient, $r_{s} 0 \cdot 74$ ).

The most plausible explanation for the variation in weight fluctuations of individuals therefore appears to lie in factors outside the household resources. One alternative consists of incidental household events, such as funerals or economic set-backs which are not systematically recorded. This would still make it hard to understand why no relationship 
patterns were found for individual years. Alternatively it might be that serious changes occur in activity patterns from one year to another. This is unlikely since food cultivation is the main activity and the food harvests in different years showed a high correlation. However, as said before, the fonio harvest failed in the second year which must have affected the activity pattern of men in September. Another substudy carried out within the same research programme showed that subjects with an insufficient cereal stock did not lose more body weight than subjects with sufficient cereal stock, but that they had different coping behaviour patterns.

The most probable factors, however, are health and disease patterns in as far as they occur independently of the socio-economic household situation. Kennedy \& Oniang'o (1990) reported that socio-economic characteristics were not the principal determinants of child nutritional status in West Kenya and suggested that health and sanitary aspects were more important. In the present study no individual data on health and sanitation were available to be associated with body-weight fluctuation.

In summary, it can be concluded that in the remote rural conditions studied here, with households mostly dependent on subsistence farming and with limited socio-economic differentiation, the magnitude of body-weight fluctuation has no relationship with household characteristics. It remains further to be established what happens in communities that are more economically developed, with the larger differentiation in income that accompanies this.

The study was supported by the STD-programme of the European Community, contract no TS2-0150-NL. We gratefully acknowledge the cooperation of the Department of Nutrition and Food Sciences of the National University of Benin and of the Africa Studies Centre in Leiden, the Netherlands.

\section{REFERENCES}

Annegers, J. F. (1973). Seasonal food shortages in West Africa. Ecology of Food and Nutrition 2, 251-257.

Ategbo, E. A. D. (1993). Food and nutrition insecurity in Northern Benin: impact on growth performance of children and on year-to-year nutritional status of adults. PhD Thesis, Wageningen Agricultural University.

Christian, P., Abbi, R., Gujral, S. \& Gopaldas, T. (1989). Socioeconomic determinants of child nutritional status in rural and tribal India. Ecology of Food and Nutrition 23, 31-38.

Dugdale, A. E. \& Payne, P. R. (1987). A model of seasonal changes in energy balance. Ecology of Food and Nutrition 19, 231-245.

Durnin, J. V. G. A., Drummond, S. \& Satyanarayana, K. (1990). A collaborative EEC-study on seasonality and marginal nutrition. The Glasgow-Hyderabad study. European Journal of Clinical Nutrition 44, Suppl. 1, 19-29.

Ferro-Luzzi, A., Scaccini, C., Taffese, S., Aberra, B. \& Demeke, T. (1990). Seasonal energy deficiency in Ethiopian rural women. European Journal of Clinical Nutrition 44, Suppl. 1, 7-18.

Guyer, J. I. (1986). Intra household processes and farming systems research: perspectives from anthropology. In Understanding Africa's Rural Households and Farming Systems, pp. 92-104 [J. L. Moock, editor]. Boulder: Westview.

Haaga, J. (1986). Child malnutrition in rural Kenya : a geographic and agricultural classification. Ecology of Food and Nutrition 18, 297-307.

Kennedy, E. (1983). Determinants of family and preschooler food consumption. Food and Nutrition Bulletin $\mathbf{5}$, $22-29$.

Kennedy, E. \& Oniang'o, R. (1990). Health and nutrition effects of sugar cane production in south-western Kenya. Food and Nutrition Bulletin 12, 261-267.

Longhurst, R. (1986). Seasonality and poverty. IDS Bulletin 17, 1-67.

McNeill, G., Payne, P. R., Rivers, J. P. W., Enos, A. M. T., de Britto, J. \& Mukarji, D. S. (1988). Socioeconomic and seasonal patterns of adult energy nutrition in a South Indian village. Ecology of Food and Nutrition 22, 85-95.

Nabarro, D. (1984). Social, economic, health, and environmental determinants of nutritional status. Food and Nutrition Bulletin 6, 8-32.

Niemeyer, R., Foeken, D. \& Klaver, W. (1991). Seasonality in the Coastal Lowlands of Kenya. Part 4/5: Food Consumption and Anthropometry. Report no. 38/1991, African Studies Centre, Leiden, The Netherlands. 
Rosetta, L. (1986). Sex differences in seasonal variations of the nutritional status of Serere adults in Senegal. Ecology of Food and Nutrition 18, 231-244.

Sahn, D. E. (1989). A conceptual framework for examining the seasonal aspects of households food security. In Seasonal Variability in Third World Agriculture. The Consequences for Food Security, pp. 20-56 [D. E. Sahn, editor]. Baltimore and London: J. Hopkins University Press.

Schultink, J. W. (1991). Seasonal changes in energy balances of rural Beninese women. PhD Thesis, Agricultural University of Wageningen.

Schultink, J. W., Klaver, W., van Wijk, H., van Raaij, J. M. A. \& Hautvast, J. G. A. J. (1990). Body weight changes and basal metabolic rates of rural Beninese women during seasons with different energy intakes. European Journal of Clinical Nutrition 44, Suppl. 1, 31-40.

Teokul, W., Payne, P. \& Dugdale, A. (1986). Seasonal variations in nutritional status in rural areas of developing countries: a review of literature. Food and Nutrition Bulletin 8, 7-10.

Université Nationale du Bénin (1992). Le Bénin en Chiffres (Figures of Benin). Août 1992. Faculté des Sciences Agronomiques, Département Economique et Sociologie Rurales, Section Economie Rurale.

Valverde, V., Martorell, R., Mejia-Pivaral, V., Delgado, H., Lechting, A., Teller, C. \& Klein, R. E. (1977). Relationship between family land availability and nutritional status. Ecology of Food and Nutrition 6, 1-7. 